\title{
Some safety aspects of in vitro fertilization and pre-embryo freezing
}

\author{
Jan Martin Maltau \\ Department of Obstetrics and Gynecology, Institute of Clinical Medicine, University of Tromso, \\ Tromsø, Norway
}

Key words: Fertilization, in vitro; Pre-embryo freezing

With the successful introduction of in vitro fertilization (IVF) by Steptoe and Edwards in 1978 [1] a new and enthusiastic era in the therapy of tubal infertility as well as other causes was introduced. IVF and related methods for assisted reproduction are now a routine treatment in most parts of the world. Also since 1983 the pre-embryo freezing and thawing process has become clinical practice at most IVF centers. This method enables surplus embryos to be replaced in a later unstimulated cyclus, thereby increasing the overall possibility of pregnancy [2].

A common feature of all the new reproductive technologies and embryo freezing methods is that they are based on treatment procedures that are definitively non-physiological. It is therefore an obvious commitment for the medical profession to be continuously alert for the possibility, albeit hypothetical, that these new technologies may have unpredictable and even harmful effects on the woman or her offspring.

Whereas some of the more frequent immediate complications and risks such as ovarian hyperstimulation, puncture lesions and early and late pregnancy problems are relatively easy to assess, the risks related to rarer complications require more careful registrations of a large number of cases. Possible adverse effects detectable only later in life, will be even more difficult to reveal. The direct adverse reactions of drugs administered in the process of in vitro fertilization will be dealt with in a separate paper in this journal. At present there are, however, indications that ovulation induction medication per se may cause neural tube defects [3]. A few examples of hypothetical long-term effects can also advanced. It is well documented that both pregnancy and the combined type of oral contraceptive reduce the risk of

Correspondence to: J.M. Maltau, Dept. of Obstetrics and Gynecology, Inst. of Clinical Medicine, University of Tromsø, Tromsø, Norway. 
ovarian cancer, probably due to reduced ovarian mitotic activity during anovulation [4].

It may therefore be a logical concern that the tremendous rise in ovarian mitotic activity during ovarian hyperstimulation could influence the risk of ovarian neoplasia in an undesirable direction. A few reports of other types of neoplasia following induced ovarian hyperstimulation have recently been published $[5,6]$. Furthermore, the maternal supraphysiological estrogen concentrations and the freezing and thawing procedures may increase the risk of induced malformations or other deleterious effects on the genome. The risk of behaviour teratology similarly has to be taken into consideration.

Until now, no such harmful late complications affecting the offspring have in fact been registered, but medical history has taught us that late events may be difficult to trace back to medical treatments in the past. It would therefore be a wise precaution to make efforts to encourage the establishment of long-term prospective nationwide surveillance of IVF mothers and their offspring, which is sufficiently sensitive to make it possible to detect any deleterious consequence of the various IVF treatment modalities.

Registers already set up in the U.S.A., Australia and several other countries deal primarily with the reporting of the various practices and the obstetrical results [7-9] obtained. They do not fulfil the task of detecting possible late occurring complications or deficiencies. The establishment of special registry systems designed to cope with these problems is a definite and necessary challenge for the medical profession. In Norway we have since 1989, a national registry of all IVF pregnancies [10]. The purpose of this register is to monitor both the short- and long-term outcome for the mothers and their offspring. We have experienced some problems due to the very strict regulations regarding data confidentiality, but these obstacles are now likely to be overcome.

\section{References}

1 Steptoe PC, Edwards RG. Birth after the reinplantation of a human embryo. Lancet 1978;(8085)2:336.

2 Testart J, Lasalle B, Belaisch-Allhart $\mathbf{J}$ et al. High pregnancy rate after early human embryo freezing. Fertil Steril 1986;46:268-272.

3 Cornel MC, Kate LPT, Dukes MNG et al. Ovulation induction and neural tube defects. Lancet $1989 ;(8651) 1: 1386$.

4 Goldzieher JW. Hormonal contraception: benefits versus risks. Am J Obstet Gynecol 1987;157:10231028.

5 Flam, F, Lundstrom V, Lindstedt J, Silfversward C, Choriocarcinoma of the fallopian tube associated with induced superovulation in an IVF program; a case report. Eur J Obstet Gynecol Reprod Biol 1989;33:183-186.

6 Laing RW, Glaser MG, Barrett GS. A case of breast carcinoma in association with in vitro fertilization. J R Soc Med 1989;82:503-504.

7 Unsigned. In vitro fertilization-embryo transfer in the United States: 1988 results from the IVF-ET registry. Fertil Steril 1990;53:13-20.

8 Unsigned. IVF and GIFT pregnancies. Australia and New Zealand, 1987. Sydney, 1988. National Perinatal Statistics Unit. ISSN 1030-4711.

9 Wildeman R, Korell M, Strowitxki T, Hepp H. Schwangerschafsverlauf nach In-Vitro-fertilization und Embryotransfer. Z Geburtshilfe Perinatol 1990;194:1-7.

10 Maltau JM. Nedfrysing av humane preembryoer. Tidsskr Nor Lægeforen 1990;110:20-21. 